\title{
Correction to: Effect of radiochemotherapy on T2* MRI in HNSCC and its relation to FMISO PET derived hypoxia and FDG PET
}

Nicole Wiedenmann ${ }^{1,4,5^{*}}$, Hatice Bunea ${ }^{1,4,5}$, Hans C. Rischke ${ }^{1,3,4,5}$, Andrei Bunea ${ }^{1,4,5}$, Liette Majerus ${ }^{1,4,5}$, Lars Bielak ${ }^{2}$, Alexey Protopopov', Ute Ludwig ${ }^{2}$, Martin Büchert ${ }^{2}$, Christian Stoykow ${ }^{3,4,5}$, Nils H. Nicolay ${ }^{1,4,5}$, Wolfgang A. Weber ${ }^{6}$, Michael Mix ${ }^{3,4,5}$, Philipp T. Meyer ${ }^{3,4,5}$, Jürgen Hennig ${ }^{2,4,5}$, Michael Bock ${ }^{2,4,5}$ and Anca L. Grosu ${ }^{1,4,5}$

\section{Correction}

Following the publication of this article [1], the authors noticed that Figs. 2, 3, 4 and 5 were in the incorrect order and thus had incorrect captions.

The images that were incorrectly published as Figs. 2, 3, 4 and 5 should have been published as Figs. 4, 5, 2 and 3 respectively.

The correct versions of Figs. 2, 3, 4 and 5 with captions have been included in this Correction.

The original article has been corrected.

\begin{abstract}
Author details
'Department of Radiation Oncology, Medical Center University of Freiburg, Faculty of Medicine, University of Freiburg, Freiburg, Germany. ${ }^{2}$ Department of Radiology, Medical Physics, Medical Center University of Freiburg, Faculty of Medicine, University of Freiburg, Freiburg, Germany. ${ }^{3}$ Department of Nuclear Medicine, Medical Center University of Freiburg, Faculty of Medicine, University of Freiburg, Freiburg, Germany. ${ }^{4}$ German Cancer Consortium (DKTK), Partner Site Freiburg, Freiburg, Germany. ${ }^{5}$ German Cancer Research Center (DKFZ), Heidelberg, Germany. ${ }^{6}$ Clinic for Nuclear Medicine, Technische Universität München, Munich, Germany.
\end{abstract}

Received: 17 September 2018 Accepted: 17 September 2018 Published online: 21 September 2018

\section{Reference}

1. Wiedenmann, et al. Radiat Oncol. 2018;13:159. https://doi.org/10.1186/

s13014-018-1103-1.

\footnotetext{
* Correspondence: nicole.wiedenmann@uniklinik-freiburg.de ${ }^{1}$ Department of Radiation Oncology, Medical Center University of Freiburg, Faculty of Medicine, University of Freiburg, Freiburg, Germany

${ }^{4}$ German Cancer Consortium (DKTK), Partner Site Freiburg, Freiburg, Germany

Full list of author information is available at the end of the article
}

(c) The Author(s). 2018 Open Access This article is distributed under the terms of the Creative Commons Attribution 4.0 International License (http://creativecommons.org/licenses/by/4.0/), which permits unrestricted use, distribution, and reproduction in any medium, provided you give appropriate credit to the original author(s) and the source, provide a link to the Creative Commons license, and indicate if changes were made. The Creative Commons Public Domain Dedication waiver (http://creativecommons.org/publicdomain/zero/1.0/) applies to the data made available in this article, unless otherwise stated. 

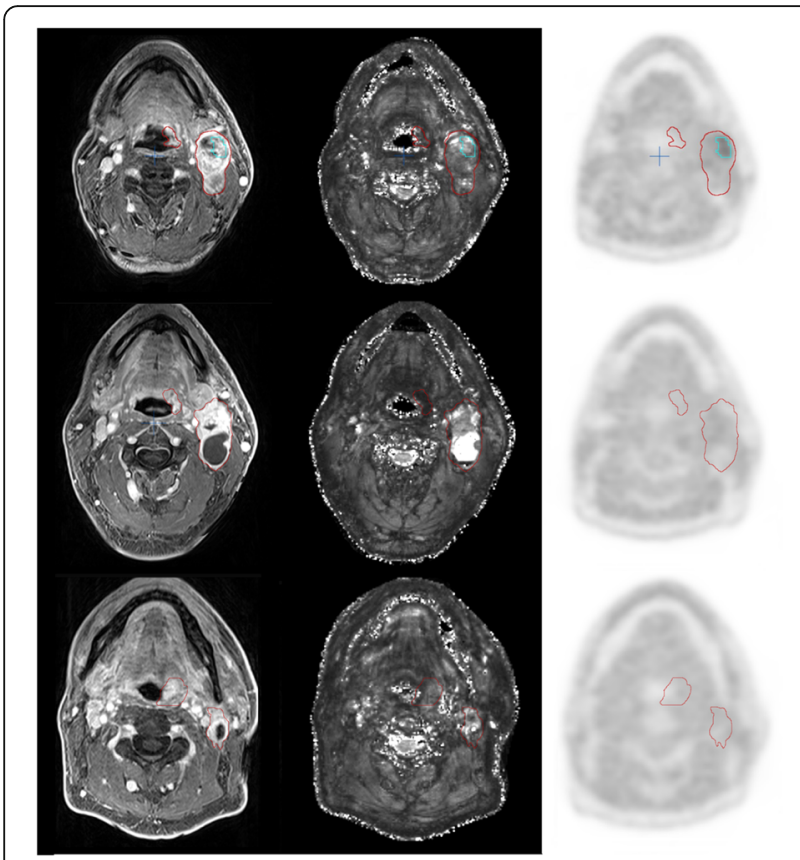

Fig. 2 Representative example of imaging modalities MRI T1, T2* and FMISO-PET. Primary tumour and lymph node metastasis (pt. 5, tonsillar carcinoma) at week 0, 2, and 5 (upper, middle, lower panel): co-registered image sets from MRI T1, MRI T2*, FMISO-PET (left to right). Red contours: GTV-T, GTV-LN. Blue contour: HSV-LN
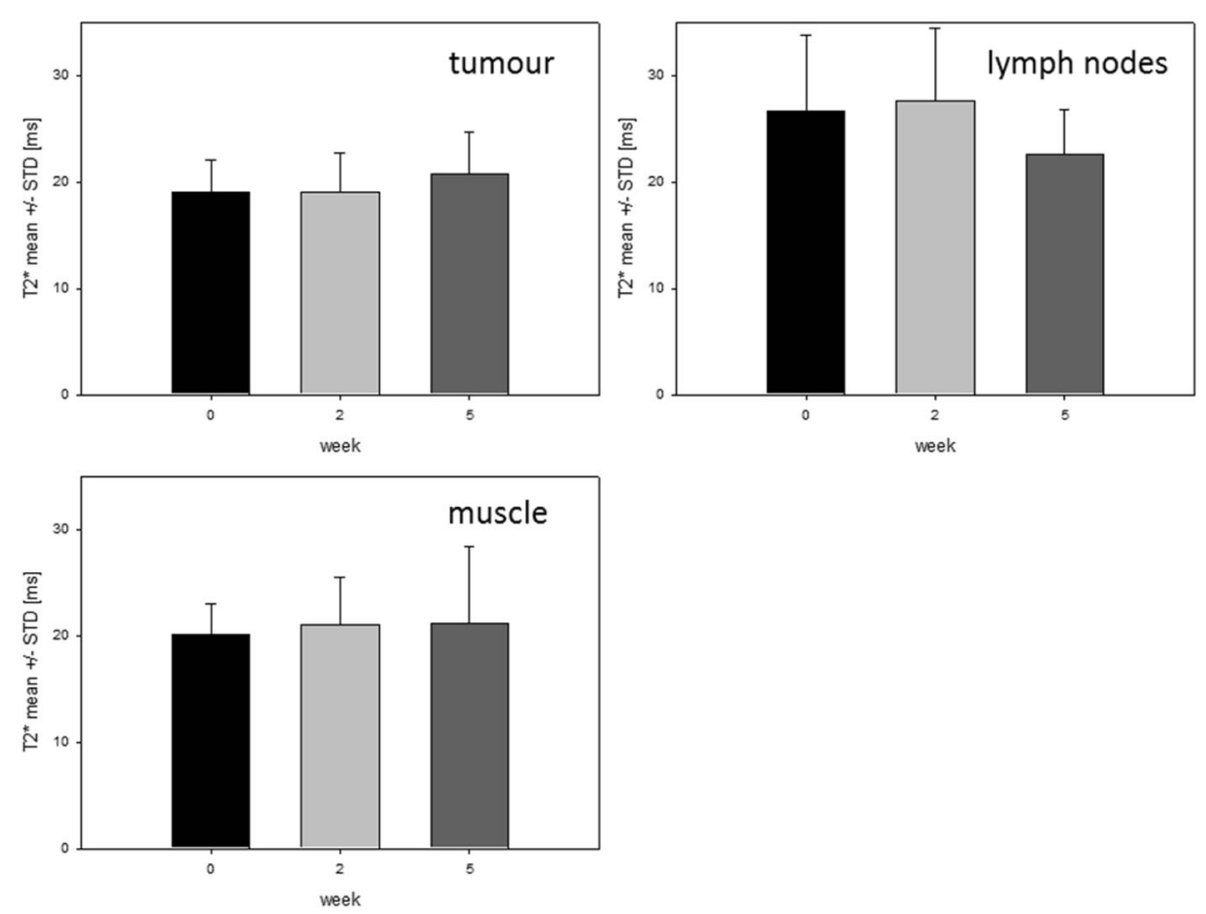

Fig. 3 Time course of T2* values within volumes. T2* mean \pm STD within tumour, lymph nodes and normal tissue for all patients $(n=10)$ 

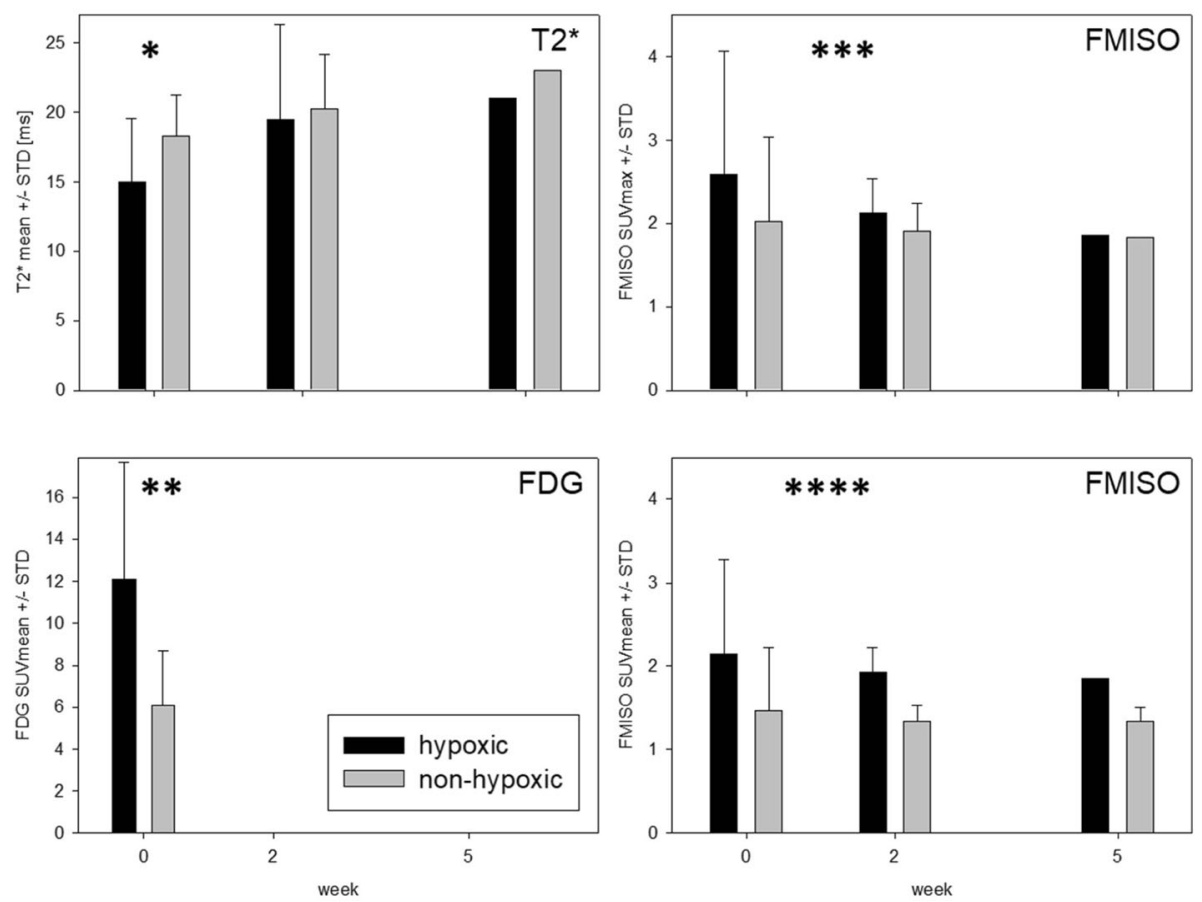

Fig. 4 Hypoxic tumour subvolumes: T2* values vs. FDG uptake and FMISO uptake. T2* values (ms) were lower and FDG uptake was higher within hypoxic tumour subvolumes as compared to non-hypoxic tumour subvolumes $\left({ }^{*} p=0.051,{ }^{* *} p=0.026\right)$. FMISO uptake was higher within hypoxic tumour subvolumes than within non-hypoxic tumour subvolumes $\left({ }^{* *} p=0.029, p=0.072\right.$, $\left.{ }^{* * *} p=0.003, p=0.0001\right)$ 


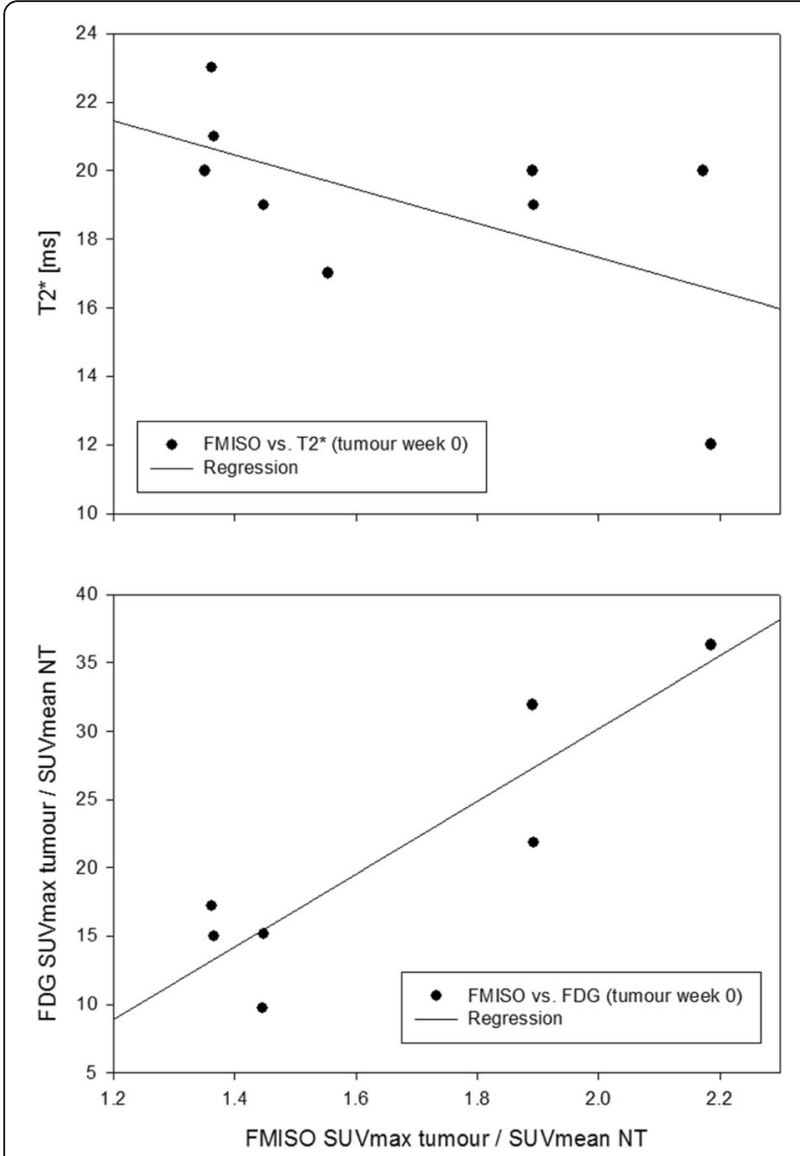

Fig. 5 Correlation of FMISO uptake with mean $2^{*}$ and FDG uptake. Plots showing correlation within GTV-T at baseline 